\title{
Modeling of asynchronous motor operation modes for the correct selection of voltage regulation devices
}

\author{
Azat Akhmetshin ${ }^{1, *}$, George Marin ${ }^{1,2}$, and Dmitrii Mendeleev ${ }^{1,2}$ \\ ${ }^{1}$ Kazan State Power Engineering University, 420066 Kazan st. Krasnoselskaya 51, Russia \\ ${ }^{2}$ JSC "Tatenergo" branch "Kazan CHP-2", 420036 Kazan st. Tatsevskaya 11, Russia
}

\begin{abstract}
Many electrical appliances are used in production and in everyday life, which include elements that are extremely sensitive to voltage deviations from acceptable values. Failure in their work can cause equipment failure or a breakdown in technological processes. There are a number of technical solutions to solve this problem, one of which is the using of voltage control devices such as boost transformers. The principle of operation of booster transformers is the introduction of a longitudinal EMF into the electric circuit, which provides booster. The choice of voltage regulation devices consists in determining its power and the required transformation ratio. The latter needs some justification, because it cannot be formally accepted: if it is necessary to increase the voltage, for example by $5 \%$, it is enough to introduce a longitudinal EMF of $5 \%$ of the nominal voltage into the electric circuit. This is due to the fact that with increasing voltage from the load side, the power consumption also increases, which causes an increase in voltage drop compared to modes in the absence of voltage regulation devices. Thus, the load will receive a slightly lower voltage level in comparison with the desired one.
\end{abstract}

\section{Introduction}

It is extremely difficult to maintain the voltage at the consumer unchanged and equal to the nominal. The characteristics of individual electrical receivers set the limits for voltage deviations.

Slow changes in power supply voltage (typically longer than 1 minute) are usually due to changes in electrical load.

Electric power quality indicators related to slow changes in the supply voltage are negative $\delta \mathrm{U}_{(-)}$and positive $\delta \mathrm{U}_{(+)}$deviations of the supply voltage at the point of transmission of electrical energy from the nominal value, $\%$ :

$$
\begin{aligned}
& \delta \mathrm{U}_{(-)}=\left[\frac{\left(\mathrm{U}_{0}-\mathrm{U}_{\mathrm{m}(-)}\right)}{\mathrm{U}_{0}}\right] * 100, \%, \\
& \delta \mathrm{U}_{(+)}=\left[\frac{\left(\mathrm{U}_{\mathrm{m}(+)}-\mathrm{U}_{0}\right)}{\mathrm{U}_{0}}\right] * 100, \%,
\end{aligned}
$$

where $\mathrm{U}_{\mathrm{m}(-)}, \mathrm{U}_{\mathrm{m}(+)}$ are the values of the power supply voltage, lower than $\mathrm{U}_{0}$ and larger $\mathrm{U}_{0}$, respectively, averaged over a time interval of 10 minutes in accordance with the requirements of State Standard 33073-2014 "Electric energy. Electromagnetic compatibility of technical equipment. Control and monitoring of electric power quality in the public power supply systems"[8].

$\mathrm{U}_{0}$ - voltage equal to standard rated voltage $U_{n}$ or matched voltage $U_{c}$.
The standard rated voltage $U_{n}$ is $220 \mathrm{~V}$ in low voltage electrical networks (between phase and neutral conductors for single-phase and four-wire three-phase systems) and $380 \mathrm{~V}$ (between phase conductors for threeand four-wire three-phase systems). The following standards are established for the above-mentioned indicators of electric power quality: positive and negative voltage deviations at the electric energy transmission point must not exceed $10 \%$ of the nominal or agreed voltage value during $100 \%$ of the time interval of one week.

Permissible values of positive and negative voltage deviations at the points of common connection should be established by the network organization, taking into account the need to comply with the norms of this standard at the points of transmission of electrical energy.

Conditions must be provided in the consumer's electrical network under which the deviations of the supply voltage at the terminals of the electrical receivers do not exceed the permissible values established for them when meeting the requirements of this standard for the quality of electricity at the point of transmission of electrical energy.

Induction regulators, adjustable autotransformers, voltage boosting transformers and linear regulators can be classified as booster devices [20]. Such devices act on the resulting voltage at the consumer or receiver by creating additional EMF, the vector of which is superimposed on the main voltage according to, counter or at some angle, as is the case in some schemes of

* Corresponding author: ahmetshin.ar@mail.ru 
booster transformers that perform "transverse" regulation.

A booster transformer is a device that serves to regulate voltage and consists of two independent units, a "series" transformer, the primary winding of which is connected in series to the line cut, and a special control transformer or autotransformer. Booster transformer is mainly used for local voltage regulation. The voltage in the regulated line differs from the voltage of the mains by the amount of additional EMF serial transformer.

Typically, voltage regulation is carried out in steps; its smoothness depends on the number of control branches of the supply transformer. Booster transformer allows you to get additional EMF phase-shifted relative to the main voltage. The shear angle depends on the switching circuit of the control transformer and for the simplest schemes is $0^{\circ}, 30^{\circ}, 60^{\circ}$ and $90^{\circ}$.

Transformers creating an additional voltage that coincides in phase with the main voltage are called boost voltage transformers with "longitudinal" regulation, and creating additional voltage, shifted by a certain angle, with "transverse" regulation.

The booster transformer is usually characterized by "throughput power", i.e. power transmitted over the line into which the serial winding is included, and "own power" - the make-up device itself.

The operating mode of the power source, circuit resistance. Voltage deviations are not always in the range of acceptable values.

Voltage regulation is the process of changing the voltage level in a characteristic accurate electrical system using special technical means. The historical development of methods and methods for regulating voltage and reactive power occurs from the lowest hierarchical levels of energy system control to the highest. In particular, voltage regulation in the central power supply networks of distribution networks - at regional substations $[1,4,5]$, where the transformation coefficients $\left(\mathrm{k}_{\mathrm{T}}\right)$ change - is supported by the voltage of consumers when changing their operating mode.

A large number of induction motors are used in agriculture and industrial enterprises. The change in the consumed active and reactive power when choosing voltage control devices has not been considered by anyone [7].

A mechanism with a "ventilatory" mechanical transmission was investigate in the work. The mechanism in which the coefficient of proportionality of speed and generalization of the results were used.

Consider the circuit diagram, figure 1. As a load, we consider three asynchronous motors with a capacity of $15 \mathrm{~kW}, 37 \mathrm{~kW}, 110 \mathrm{~kW}$ with a rated voltage $U_{\mathrm{n}}=380 \mathrm{~V}$.

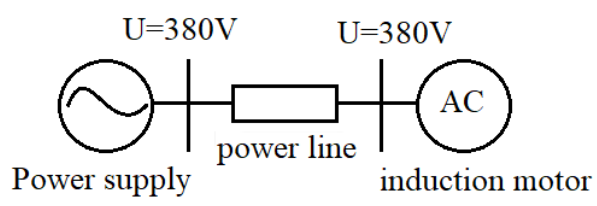

Fig. 1. Schematic diagram of connecting an induction motor.

The effect of voltage boosting depends on the ratio between the resistances of the power supply line and the load and generally acts to reduce the resulting voltage [2, 3].

\section{Modeling induction motor}

We model the circuit diagram in the MATLAB/ Simulink environment to plot the dependences of the power consumption on the voltage level, taking into account the different operating conditions of the induction motor [4-6].

The moment of resistance of an induction motor is represented by the formula:

$$
M_{c}=M_{T P}+\left(k_{e l} * M_{n o m}-M_{T P}\right) *\left(\omega / \omega_{\text {synch }}\right)^{\gamma} \text {, }
$$

where $\mathrm{M}_{\mathrm{TP}}$ is the initial moment at $\mathrm{s}=1$ or $\omega=0$, usually determined by friction forces; $k_{\mathrm{el}}$ is the engine load factor at synchronous angular velocity (the moment of resistance of the mechanism at $\omega=1$, expressed in fractions of the nominal moment of the engine); $\gamma$ is an exponent characterizing this mechanism $[9,10]$.

The engine operation model for $\gamma=2$ is shown in figure 2 , for $\gamma=5$ it is shown in figure 3. To determine the dependence of power consumption on engine load factor $\mathrm{k}_{\mathrm{el}}$ which varies from $30 \%$ to $70 \%$, and the initial moment of $\mathrm{M}_{\mathrm{TP}}$ which varies from $10 \%$ to $50 \%$.

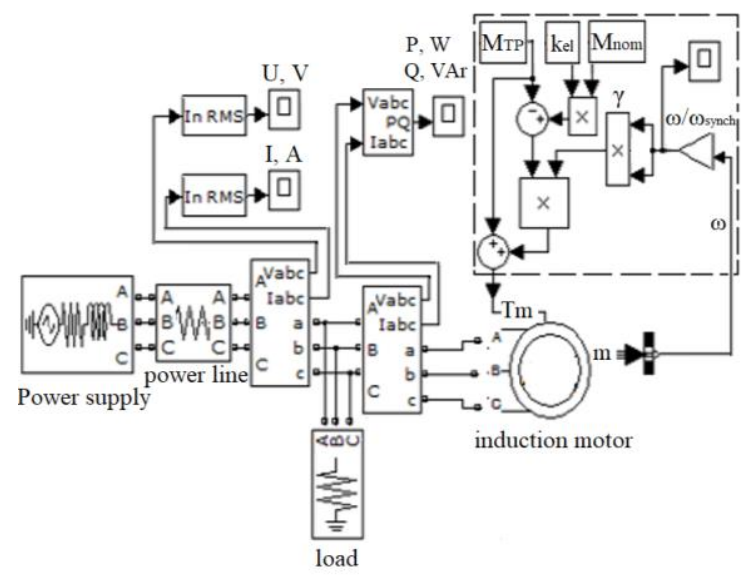

Fig. 2. Engine operation diagram for $\gamma=2, \mathrm{k}_{\mathrm{el}}=30-70 \%, \mathrm{M}_{\mathrm{TP}}$ $=10-50 \%$.

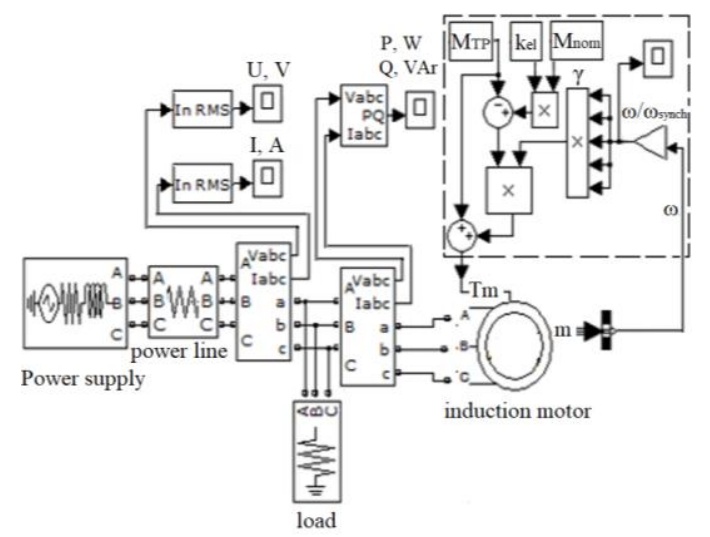

Fig. 3. Engine operation diagram for $\gamma=5$, $\mathrm{k}_{\mathrm{el}}=30-70 \%, \mathrm{M}_{\mathrm{TP}}$ $=10-50 \%$. 
A 3-Phase Source block (designed to simulate a three-phase voltage source) is used as a power center, which includes three voltage sources connected to a star with a neutral wire [13-16]. The Three-Phase Series RLC Branch block was used as the power line because the inductive resistance of the line is neglected in the 0.4 $\mathrm{kW}$ network due to the small length [17-19]. The block in our case models a three-phase circuit consisting of three active resistances. An asynchronous motor is represented by the Asynchronous Machine block simulating an asynchronous electric machine in a motor mode $[11,12]$. The operation mode is determined by the law of the electromagnetic moment of the machine. The block contains several preset models of the induction motor. As an asynchronous motor we use an asynchronous motor with a power of $15 \mathrm{~kW}, 37 \mathrm{~kW}, 110$ $\mathrm{kW}$ and a rated voltage of $380 \mathrm{~V}$ and a frequency of 50 $\mathrm{Hz}$ specified by the MATLAB / Simulink program. The Tm port is designed to provide a moment of resistance to movement. The moment of resistance to movement is given by formula (1).

Define the synchronous angular velocity:

$$
\omega_{\text {synch }}=\eta * \frac{2 * \pi}{60}
$$

where $\eta$ is rotational speed of an induction motor.

Define the rated torque at a synchronous speed for the considered induction motors:

$$
\mathrm{M}_{\text {nom.s }}=\frac{\mathrm{P}_{\mathrm{m}}}{\omega_{\text {synch }}}
$$

where $\mathrm{P}_{\mathrm{m}}$ is the rated engine power indicated in the engine model of the MATLAB/Simulink program.

For an induction motor with a rated power of $\mathrm{P}_{\mathrm{M}}=$ $15 \mathrm{~kW}: \eta=1460 \mathrm{rpm}, \mathrm{M}_{\text {nom.s }}=95.49 \mathrm{~N}^{*} \mathrm{~m}$, for an induction motor of $\mathrm{P}_{\mathrm{M}}=37 \mathrm{~kW}: \eta=1480 \mathrm{rpm}, \mathrm{M}_{\text {nom.s }}=$ $235.56 \mathrm{~N}^{*} \mathrm{~m}$, for an induction motor $\mathrm{P}_{\mathrm{m}}=110 \mathrm{~kW}: \eta=$ $1487 \mathrm{rpm}, \mathrm{M}_{\text {nom.s }}=700.28 \mathrm{~N}^{*} \mathrm{~m}$.

The load factor for active and reactive power is determined by:

$$
\mathrm{k}_{\mathrm{l}}=\frac{\mathrm{P}_{\mathrm{mw}}}{\mathrm{P}_{\mathrm{n}}} \text {, }
$$

where $\mathrm{P}_{\mathrm{mw}}$ is the active power consumed by an induction motor at various levels of operating voltage, $\mathrm{U}_{\mathrm{w}}$, which is calculated relative to the nominal $\left(0.7-1.1 * \mathrm{U}_{\mathrm{n}}\right)$ with the condition that $\mathrm{k}_{\mathrm{el}}=30-70 \%$ and $\mathrm{M}_{\mathrm{TP}}=10-50 \% ; \mathrm{P}_{\mathrm{n}}$ is the rated active power of the engine.

The dependence of $\mathrm{k}_{1}$ on the supply voltage for two variants of mechanisms is presented in figures 4 and 5 .

Figures 4 and 5 show that engines of different power, initially equally loaded, have approximate dependencies that slightly depend on the voltage level, this suggests that for them it is possible to take the load factor the same within a few percent of the error.

Also from figures 4 and 5 it can be seen that the $\mathrm{M}_{\mathrm{TP}}$ value has little effect on the load factor, which makes it possible to group the motors in one equivalent exactly by the value of this coefficient.

Determine the resistance at rated voltage by the formula:

$$
\mathrm{r}_{\mathrm{nb}}=\frac{\mathrm{U}_{\mathrm{n}}^{2}}{\mathrm{P}_{\mathrm{mk}}^{\prime}}
$$

where $U_{n}$ is the rated voltage, $\mathrm{P}_{m k}$ is the consumed active power at the rated voltage $U_{n}$ and under various conditions of change $\mathrm{M}_{\mathrm{TP}}=10-50 \%, \mathrm{k}_{\mathrm{el}}=30-70 \%$.
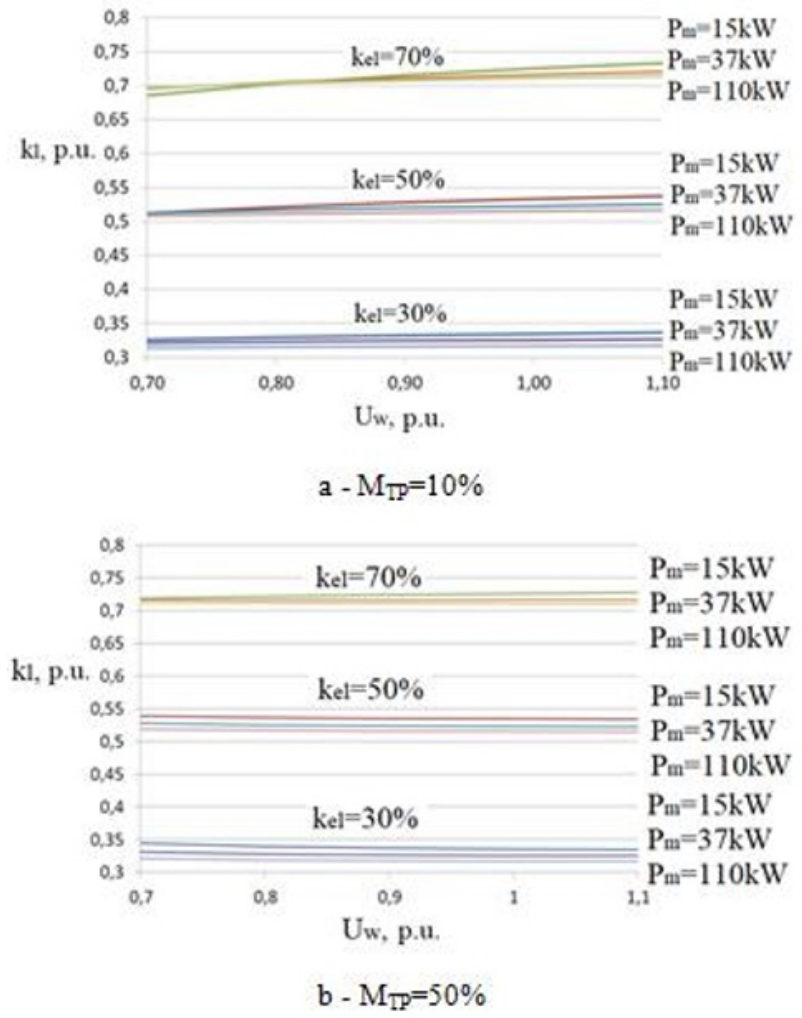

Fig. 4. The dependence of the load factor of the active power on the mains voltage for an induction motor $\gamma=2$. 


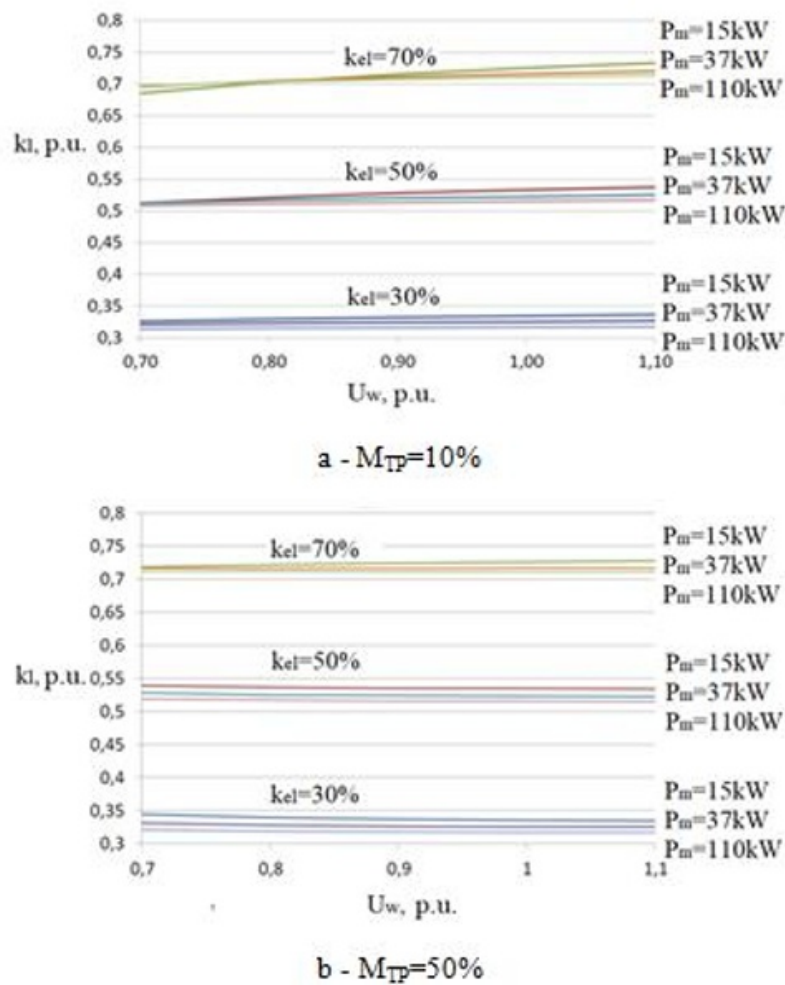

Fig. 5. The dependence of the load factor of the active power on the mains voltage for an induction motor $\gamma=5$.

We determine the active resistance under the condition $\mathrm{U}_{\mathrm{w}}=0.7-1.1 * \mathrm{U}_{\mathrm{n}}$ by the formula:

$$
\mathrm{r}_{\mathrm{w}}=\frac{\mathrm{U}_{\mathrm{w}}^{2}}{\mathrm{P}_{\mathrm{mw}}}
$$

Figure 6 shows a graph of resistance changes versus voltage level. From which (figure 6) it is seen that the active resistance at various values of $\mathrm{M}_{\mathrm{TP}}=10-50 \%, \mathrm{k}_{\mathrm{el}}$ $=30-70 \%$ and engine power varies according to one law and is within $5 \%$ of the error, and varies significantly from the voltage level. The actual resistance value can be determined by the formula:

$$
\begin{aligned}
& \mathrm{r}_{\mathrm{W}}=\frac{\mathrm{r}_{\mathrm{W}}}{\mathrm{r}_{\mathrm{U}_{\mathrm{W}}^{\prime}}} * \mathrm{r}_{\mathrm{W}}^{\prime}, \\
& \mathrm{x}_{\mathrm{W}}=\frac{\mathrm{x}_{\mathrm{U}_{\mathrm{W}}}}{\mathrm{x}^{\prime} \mathrm{U}_{\mathrm{w}}} * \mathrm{x}_{\mathrm{W}}^{\prime},
\end{aligned}
$$

where $\mathrm{r}^{\prime} \mathrm{U}_{\mathrm{w}}, \mathrm{x}^{\prime} \mathrm{U}_{\mathrm{w}}$ are the load resistance at $\mathrm{U}_{\mathrm{p}}$, expressed in p.u. .; $\mathrm{r}_{\mathrm{U}_{\mathrm{W}}}, \mathrm{x}_{\mathrm{U}_{\mathrm{W}}}$ - load resistance at $\mathrm{U}_{\mathrm{P}}$, expressed in named units; $r_{p}^{\prime}, x_{p}^{\prime}$ - load resistance at $\mathrm{U}_{\mathrm{n}}$, expressed in p.u.

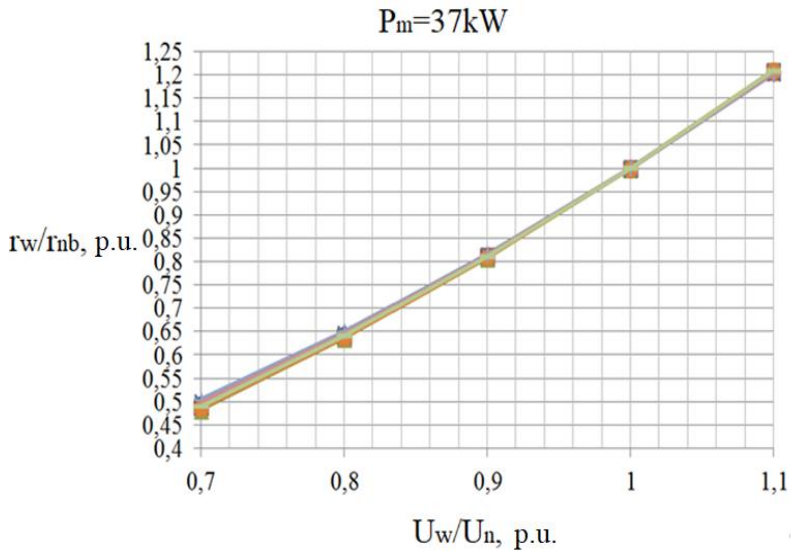

Fig. 6. Graph of changes in active resistance against voltage at $\mathrm{M}_{\mathrm{TP}}=10-50 \%$ and $\mathrm{k}_{\mathrm{el}}=30-70 \%$.

It is necessary to determine $\operatorname{tg} \phi_{\mathrm{n}}$ to determine the correction coefficient $\mathrm{k}_{\mathrm{P}}$. The $\operatorname{tg} \phi_{\mathrm{n}}$ change diagram is shown in figures 7 and 8 .

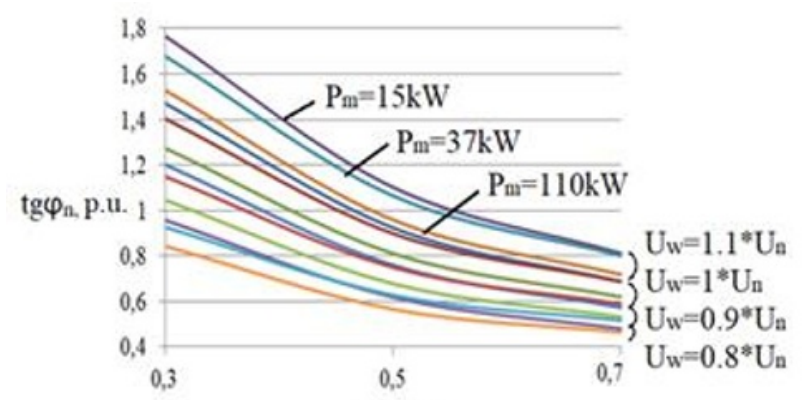

kel, p.u.

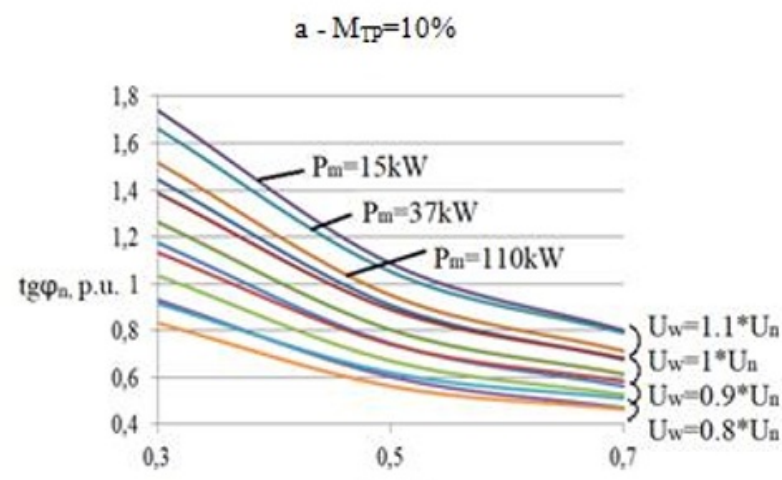

kel, p.u.

$$
\mathrm{b}-\mathrm{M}_{\mathrm{TP}}=50 \%
$$

Fig. 7. . Change in $\operatorname{tg} \phi n$ at different levels of Up relative to $\mathrm{kel}_{\mathrm{e}}$ for different values of MTP for an induction motor $\gamma=2$. 


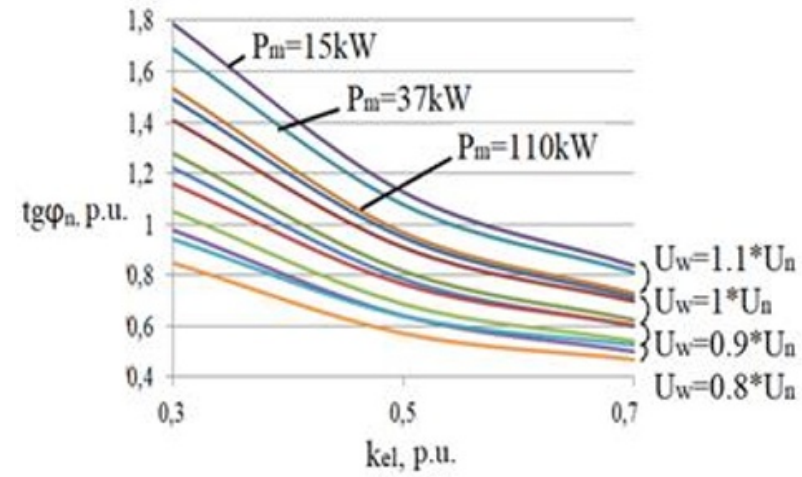

$\mathrm{a}-\mathrm{M}_{\mathrm{TP}}=10 \%$

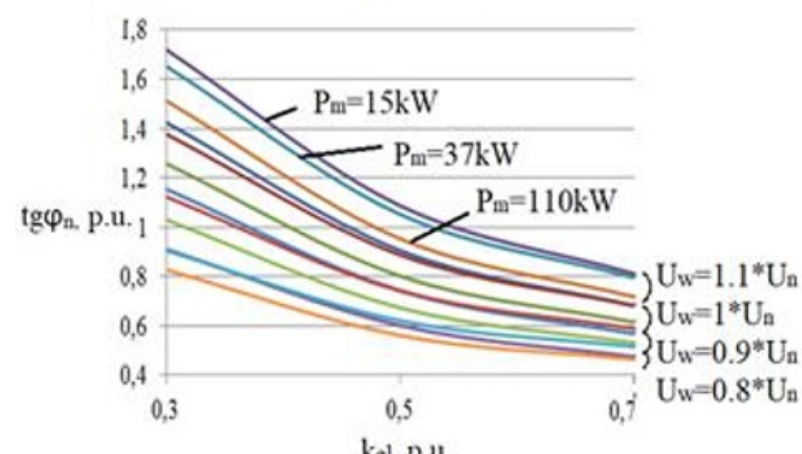

$\mathrm{b}-\mathrm{M}_{\mathrm{TP}}=50 \%$

Fig. 8. Change in $\operatorname{tg} \phi_{\mathrm{n}}$ at different levels of $U_{\mathrm{P}}$ relative to $\mathrm{k}_{\mathrm{el}}$ for different values of $\mathrm{M}_{\mathrm{TP}}$ for an induction motor $\gamma=5$.

It can be seen from figures 7 and 8 that with increasing voltage, the value of $\operatorname{tg} \phi_{\mathrm{n}}$ also increases.

The change in $\operatorname{tg} \phi_{\mathrm{n}}$ obeys one law with the variation of $\mathrm{k}_{\mathrm{el}}, \mathrm{M}_{\mathrm{TP}}$. In order to generalize the obtained $\operatorname{tg} \phi_{\mathrm{n}}$ values for various values of $\mathrm{M}_{\mathrm{TP}}$, we use the least squares method.

As a result, generalized characteristics are obtained that make it possible to determine $\operatorname{tg} \phi_{\mathrm{n}}$ for engines of different powers, neglecting $\mathrm{M}_{\mathrm{TP}}$.

To determine $\mathrm{k}_{\mathrm{w}}$, all parameters are known, and $\mathrm{k}_{\mathrm{w}}$ is determined by expression (4).

$$
\begin{aligned}
& \mathrm{k}_{\mathrm{w}}=\left|\frac{\mathrm{r}_{\mathrm{nb}} *\left(1+\mathrm{j} \operatorname{tg} \phi_{\mathrm{n}}\right)}{\left(\mathrm{r}_{10}+\mathrm{j} \mathrm{x}_{10}\right) * \mathrm{k}_{1} * 1+\mathrm{r}_{\mathrm{nb}} *\left(1+\mathrm{jtg} \phi_{\mathrm{n}}\right)}\right|= \\
& =\left|\frac{\left(1+\mathrm{j} \operatorname{tg} \phi_{\mathrm{n}}\right)}{(\alpha+\mathrm{j} \beta) * \mathrm{k}_{\mathrm{kl}}+\left(1+\mathrm{j} \operatorname{tg} \phi_{\mathrm{n}}\right)}\right|,
\end{aligned}
$$

where $\alpha=\mathrm{r}_{10} / \mathrm{r}_{\mathrm{nb}} ; \beta=\mathrm{x}_{10} / \mathrm{r}_{\mathrm{nb}}, \mathrm{k}_{\mathrm{kl}}=\mathrm{k}_{1} * 1$.

From formula (4) it can be seen that the ratio between the network and load resistances affects the magnitude of the voltage boost.

In real conditions, to determine $\mathrm{k}_{\mathrm{e}}, \operatorname{tg} \phi_{\mathrm{n}}, \mathrm{r}_{\mathrm{nb}}$, you can use clamp meters with the function of measuring power.

\section{The choice of voltage regulation device}

The problem of choosing the transformation coefficient $\left(\mathrm{k}_{\mathrm{T}}\right)$ of voltage regulation devices is to correctly take into account the value of the consumer load power, which changes with voltage $[9,10,19]$.

Let's consider two options:

1. When the voltage of the consumer changes, they remain constant $\left(\mathrm{r}_{\mathrm{n}}, \mathrm{x}_{\mathrm{n}}=\right.$ const $)$;

2. When the voltage changes, the consumer resistance changes.

Figure 9 shows a diagram based on the calculation results for $\operatorname{tg} \phi=0.4$

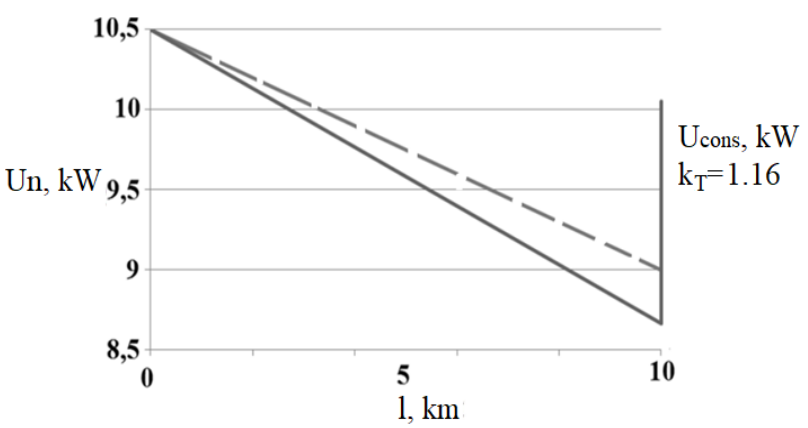

Fig. 9. The change in voltage $\left(r_{n}, x_{n}=\right.$ const $)$.

In figure 9, the voltage drop for the initial values of the load power, provided that the consumer load is constant, $\mathrm{k}_{\mathrm{T}},=1.1$, is shown by a dashed line, and the voltage drop with a constant resistance $\left(r_{n}, x_{n}=\right.$ const) is shown by a solid line.

Figure 9 shows that when the voltage on the consumer increases with a constant load resistance of the consumer, the voltage drop increases: this indicates the need to increase $\mathrm{k}_{\mathrm{T}}$ from 1.1 to 1.16 . In this scheme, it will be necessary to install two nodes, two boost transformers.

Subject to voltage changes the consumer resistance changes. To determine the resistance under the condition $\mathrm{U}_{\text {cons }}=10 \mathrm{kV}$, we use the graph of the dependence of resistance on voltage in p.u., figure 6, for fan mechanisms with $\gamma=5$ constructed using the MATLAB / Simulink simulation software.

As an example, consider the load represented by three asynchronous motors $\mathrm{P}=110 \mathrm{~kW}$ with $\mathrm{k}_{1}=0.5, \mathrm{P}=$ $37 \mathrm{~kW}$ with $\mathrm{k}_{1}=0.7, \mathrm{P}=37 \mathrm{~kW}$ with $\mathrm{k}_{1}=0.4$, the length of the power line varies $10 \mathrm{~km}$ and is made by AS -16 , figure 10 .

We neglect the power loss and voltage drop in the power transformer. 


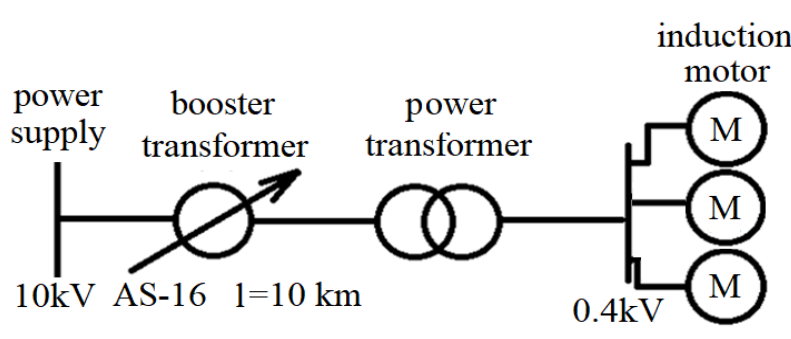

Fig. 10. Single line diagram.

To determine the resistance values at $\mathrm{U}_{\text {cons }}=10 \mathrm{kV}$, we use the formulas ( 2 and 3 ):

Having determined the resistance values using formulas (2-3), we calculate the power consumption at the beginning of the line at $\mathrm{U}_{\text {cons }}=\mathrm{U}_{\mathrm{n}}=10 \mathrm{kV}$.

Based on the calculation results for $\operatorname{tg} \phi=0.4$, a diagram is constructed, figure 11 .

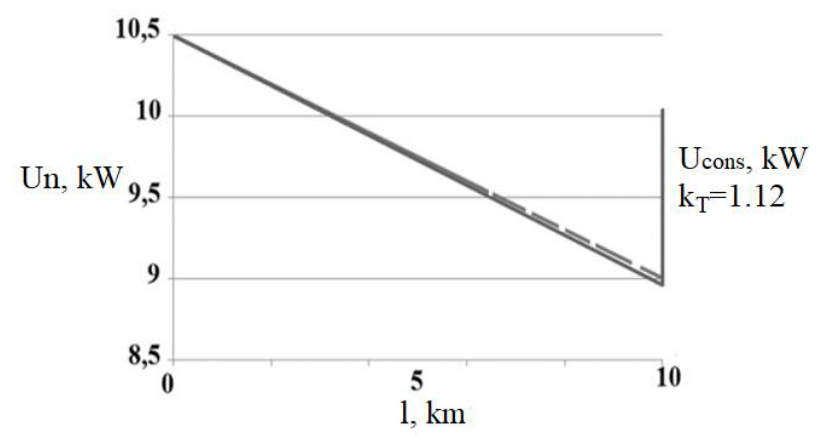

Fig. 11 Voltage change ( $\mathrm{r}_{\mathrm{n}}, \mathrm{x}_{\mathrm{n}}$ depends on $\left.\mathrm{U}_{\text {cons }}\right)$..

From figure 11 it can be seen that to increase the voltage level to the nominal value, $\mathrm{k}_{\mathrm{T}}$ should be equal to 1.12 .

\section{Conclusion}

As can be seen from the results obtained, when choosing the coefficient of transformation of voltage regulation devices, the nature of the dependence of the load power on its voltage should be taken into account. So the transformation coefficient, calculated under the condition of constant power when the load voltage changes, will turn out to be somewhat underestimated, which does not provide the required voltage level in reality (since the magnitude of the load power changes with voltage change).

On the other hand, the calculation of the transformation coefficient of voltage regulating devices (resistance constant), when the supply voltage changes, will lead to the choice of an oversized transformation coefficient, this fact affects the number of boost transformers installed in one node (two or three), and the number of installed knots in a line.

The variant with which the load resistance depends on the voltage allows you to take into account the actual changes, which ensures the correct selection of the transformation coefficient.

\section{References}

[1] Y.I. Soluyanov, A.I. Fedotov, A.R. Ahmetshin, Calculation of electrical loads of residential and public buildings based on actual data, IOP Conference Series: Materials Science and Engineering 643, article no. 012051. DOI 10.1088/1757-899X/643/1/012051 (2019)

[2] K. Suslov, V. Piskunova, D. Gerasimov, E. Ukolova, A. Akhmetshin, P. Lombardi, P. Komarnicki, Development of the methodological basis of the simulation modelling of the multi-energy systems, International Scientific and Technical Conference Smart Energy Systems 2019 (SES-2019), E3S Web of Conferences 124, article no. 01049. DOI: 10.1051/e3sconf/201912401049 (2019)

[3] D.I. Mendeleev, G.E. Marin, A.R. Akhmetshin, The implementation and use of gas turbines with absorption refrigerating machine in the technological schemes of thermal power plants, 2019 International Multi-Conference on Industrial Engineering and Modern Technologies Publisher IEEE INSPEC, accession no. 19229407. DOI 10.1109/FarEastCon.2019.8934431 (2019)

[4] K. Bakhteev, A. Fedotov, R. Misbakhov, The improving efficiency of electric receivers on the industrial enterprises in case of short-term power outages, Proceedings of the 2019 20th International Scientific Conference on Electric Power Engineering Ostrava Czech Republic, 347-352. DOI 10.1109/EPE.2019.8778181 (2019)

[5] E.I. Gracheva, A.N. Alimova, Calculation methods and comparative analysis of losses of active and electric energy in low voltage devices, 2019 International Ural Conference on Electrical Power Engineering INSPEC, accession no. 19080057.

10.1109/URALCON.2019.8877627 (2019)

[6] E.I. Gracheva, A.N. Alimova, Calculating probability of faultless work of shop nets with the help of coefficients of ratio, 2019 International Russian Automation Conference INSPEC, accession no. 19090885 . DOI 10.1109/RUSAUTOCON.2019.8867727 (2019)

[7] A.B. Chubais, E.V. Ametistova, Yu.A. Udaltsova, Y.M. Urinson, Economics and management in the modern electric power industry of Russia (Moscow NP KONTs UES, 616, 2009)

[8] GOST 33073-2014, Electrical energy. Electromagnetic compatibility. Control and monitoring of the quality of electric energy in general-purpose power supply systems (2014) 
[9] Yu.S. Zhelezko, Electricity losses. Reactive power. Electricity quality: A guide for practical calculations (Moscow ENAS, 456, 2009)

[10] I.A. Danilov, K.V. Lototsky, Electric motors (Moscow Ed., 527, 1972)

[11] I.V. Chernykh, Modeling of electrical devices in MATLAB, SimPowerSystems and Simulink (Moscow DMK Press, 288, 2007)

[12] I.P. Kryuchkov, V.A. Starshinov, Yu.P. Gusev, M.V. Pirates, Transients in electric power systems (Moscow Publishing House MPEI, 416, 2008)

[13] D.I. Mendeleev, Yu.Ya. Galitskii1, G.E. Marin, A.R. Akhmetshin, Study of the work and efficiency improvement of combined-cycle gas turbine plants, International Scientific and Technical Conference Smart Energy Systems 2019 (SES-2019) E3S Web of Conferences 124, article no. $05016 . \quad$ DOI: 10.1051/e3sconf/201912405061 (2019)

[14] E.I. Gracheva, O.V. Naumov, Evaluation criteria of contact group technical state concerning electrical appliances, International Journal of pharmacy and Technology 4, 27084-27091 (2016)

[15] I. Monedero, C. Leon, J. Ropero, Classification of electrical disturbances in real time using nueral networks, IEEE Trans. Power Deliv, 1-9 (2007)

[16] J. José, G. De, A. Agüera-Pérez, J.C. PalomaresSalas, J.M. Sierra-Fernández, A. Moreno-Muñoz, A novel virtual instrument for power quality surveillance based in higher-order statistics and case-based reasoning, Mesurement 45, 18241835 (2012)

[17] International Conference on Renewable Energies and Power Quality (ICREPQ'17) Malaga (Spain), 4th to 6th April 2017, no. 15, Optimization of Residential Load Consumption during Energy Peaks using Smart Metering Rovan Refaat ElRazky, Ahmed Ali Daoud, Kamel El-serafi 227232 (2017)

[18] I. Junquera, J. García-Villalobos, I. Zamora, P. Eguía, J.I. San Martín, International conference on renewable energies and power quality (ICREPQ'17) Malaga (Spain), 4 th to 6 th April 2017, Renewable Energy and Power Quality Journal (RE\&PQJ), no. 15, Home energy management systems and electric vehicles: challenges and opportunities, 334-339 (2017). ISSN: 2172-038 X

[19] A.A. Gerasimenko, Transmission and distribution of electric energy: a manual (D: Phoenix Krasnoyarsk Publishing projects, 720, 2006)

[20] A.F. Zobaa, Shady H.E. Abdel Aleem, Power Quality in Future Electrical Power Systems, The Institution of Engineering and Technology, 440 (2017) 